\title{
Research
}

\section{Bromocriptine and insulin sensitivity in lean and obese subjects}

\author{
L Bahler ${ }^{1}$, H J Verberne ${ }^{2}$, E Brakema', R Tepaske ${ }^{3}$, J Booij ${ }^{2}$, J B Hoekstra ${ }^{1}$ and \\ F Holleman ${ }^{1}$
}

${ }^{1}$ Internal Medicine, Academic Medical Center, Amsterdam, The Netherlands ${ }^{2}$ Nuclear Medicine, Academic Medical Center, Amsterdam, The Netherlands

${ }^{3}$ Intensive Care Medicine, Academic Medical Center, Amsterdam, The Netherlands

\author{
Correspondence \\ should be addressed \\ to L Bahler \\ Email \\ I.bahler@amc.uva.nl
}

\begin{abstract}
Bromocriptine is a glucose-lowering drug, which was shown to be effective in obese subjects with insulin resistance. It is usually administered in the morning. The exact working mechanism of bromocriptine still has to be elucidated. Therefore, in this open-label randomized prospective cross-over mechanistic study, we assessed whether the timing of bromocriptine administration (morning vs evening) results in different effects and whether these effects differ between lean and obese subjects. We studied the effect of bromocriptine on insulin sensitivity in 8 lean and 8 overweight subjects using an oral glucose tolerance test. The subjects used bromocriptine in randomized cross-over order for 2 weeks in the morning and 2 weeks in the evening. We found that in lean subjects, bromocriptine administration in the evening resulted in a significantly higher post-prandial insulin sensitivity as compared with the pre-exposure visit (glucose area under the curve (AUC) $742 \mathrm{mmol} / \mathrm{L}$ * $120 \mathrm{~min}(695-818)$ vs 641 (504-750), $P=0.036$, AUC for insulin did not change, $P=0.575$ ). In obese subjects, both morning and evening administration of bromocriptine resulted in a significantly higher insulin sensitivity: morning administration in obese: insulin AUC $(55,900 \mathrm{mmol} / \mathrm{L}$ * $120 \mathrm{~min}(43,236-96,831)$ vs $36,448(25,213-57,711), P=0.012)$ and glucose AUC $P=0.069$; evening administration in obese: glucose AUC ( $735 \mathrm{mmol} / \mathrm{L}$ * $120 \mathrm{~min}(614-988)$ vs $644(568-829), P=0.017)$ and insulin AUC, $P=0.208$. In conclusion, bromocriptine increases insulin sensitivity in both lean and obese subjects. In lean subjects, this effect only occurred when bromocriptine was administrated in the evening, whereas in the obese, insulin sensitivity increased independent of the timing of bromocriptine administration.
\end{abstract}

\author{
Key Words \\ - dopamine \\ - bromocriptine \\ - insulin sensitivity \\ - obesity \\ - circadian rhythm
}

\section{Introduction}

In $30-50 \%$ of the patients with type 2 diabetes mellitus, current pharmaceutical options to reach an adequate glucose control are insufficient (1). Therefore, the search for new and better treatment options is still ongoing. Recently, a quick release variant of bromocriptine has emerged as a new glucose-lowering treatment in obese patients with type 2 diabetes mellitus. Bromocriptine is a centrally acting dopamine $\mathrm{D}_{2}$-receptor agonist, but it also weakly stimulates the dopamine $\mathrm{D}_{1}$-receptor (2). Treatment with bromocriptine was shown to improve several metabolic parameters such as glucose levels in obese patients with and without diabetes mellitus compared with placebo $(3,4,5,6,7,8,9,10)$. However, we recently performed a trial in which we administered

$$
\begin{array}{lr}
\text { http://www.endocrineconnections.org } & \text { ○ } 2016 \text { The authors } \\
\text { DOI: } 10.1530 / \text { EC-16-0051 } & \text { Published by Bioscientifica Ltd }
\end{array}
$$


bromocriptine, for 2 weeks, in the evening in 8 lean, healthy subjects. Unexpectedly, these lean healthy subjects became less insulin sensitive after using bromocriptine (11). This adverse effect of bromocriptine in lean healthy males might have been caused by two factors. First, bromocriptine might exert different effects in lean compared with obese subjects. In other words, bromocriptine may correct a pathological condition in obese patients with diabetes mellitus type 2, whereas in lean subjects, there is no pathological condition. Secondly, the timing of the bromocriptine may have interfered with the normal circadian dopamine rhythm $(12,13,14)$.

The aim of this clinical study was to gain a better understanding of the mechanism of action of bromocriptine on insulin sensitivity. First, we aimed to investigate whether bromocriptine administration for 2 weeks had a different effect on insulin sensitivity in lean compared with overweight subjects. Second, we aimed to investigate whether the timing of bromocriptine administration had an effect on insulin sensitivity (i.e. whether administration in the morning has a different effect on insulin sensitivity compared with administration in the evening).

\section{Methods}

\section{Study population}

Sixteen subjects were recruited by public advertisements in the Academic Medical Center (AMC) in Amsterdam and on websites for trial subjects, between October 2014 and August 2015.

Eligible for the study were healthy, Caucasian males between ages 18 and 35 years, with a stable weight for at least 3 months before inclusion. The subjects were either lean (BMI $19-23 \mathrm{~kg} / \mathrm{m}^{2}$ ) or overweight $\left(\right.$ BMI $\left.>27 \mathrm{~kg} / \mathrm{m}^{2}\right)$. The included subjects were age matched (lean vs overweight). None of the subjects had contraindications to the use of bromocriptine (e.g. known hypersensitivity to bromocriptine, uncontrolled hypertension, a known history of coronary artery diseases or valvulopathy, a history of severe psychiatric disorders, prolactinomas), as determined by history, physical examination and blood screening. Other exclusion criteria were use of prescription medication or drugs or a foreseen aberrant lifestyle (e.g. excessive physical exercise, night shifts, excessive alcohol intake) during the study period that would potentially influence the outcome. All subjects gave written signed voluntary informed consent before participation. The protocol was approved by the Medical Ethics Committee of the AMC. All procedures performed in this study were in accordance with the ethical standards of the institutional research committee and with the 1964 Helsinki declaration and its later amendments or comparable ethical standards.

\section{Power analysis}

Power calculation was performed using nQuery Advisor and was based on a previous study (11). Assuming an alpha of 5\%, 6 subjects were needed in each group to reach a power of $80 \%$. To enlarge power and to allow for unexpected findings, two extra subjects per group have been included. This led to a total of 16 .

\section{Study design}

This open-label randomized prospective cross-over mechanistic study consisted of 8 lean and 8 overweight subjects. All participants used bromocriptine for a period of two weeks in the morning and a period of two weeks in the evening according to a software-driven randomization order (Castor Electorinic Data Capture (EDC), Amsterdam, The Netherlands). The periods were separated by a wash-out of at least two weeks (Fig. 1). The daily bromocriptine dose administrated was $1.25 \mathrm{mg}$ (orally) during each first week and $2.50 \mathrm{mg}$ during each second week. So, the study consisted of two separate investigation periods with two preexposure measurements (visits 1 and 3), after which bromocriptine was used according to the randomization (i.e. bromocriptine in the evening or morning), which was followed by an investigation day (visits 2 and 4).

\section{Study visits}

For all study visits, subjects arrived in the morning at the clinical diabetology department after an overnight fast. Each of the four visits consisted of the same measurements. Subject's weight, wearing underwear only, was measured to the nearest $100 \mathrm{~g}$ on a calibrated mechanical scale (SECA, Hamburg, Germany). Energy expenditure (EE) was measured, and a cannula was inserted into an antecubital vein to obtain blood samples during the oral glucose tolerance test (OGTT). Subjects were instructed to keep their diet as constant as possible during study participation. To check for possible changes in eating behavior between visits, the subjects were asked to record 
A

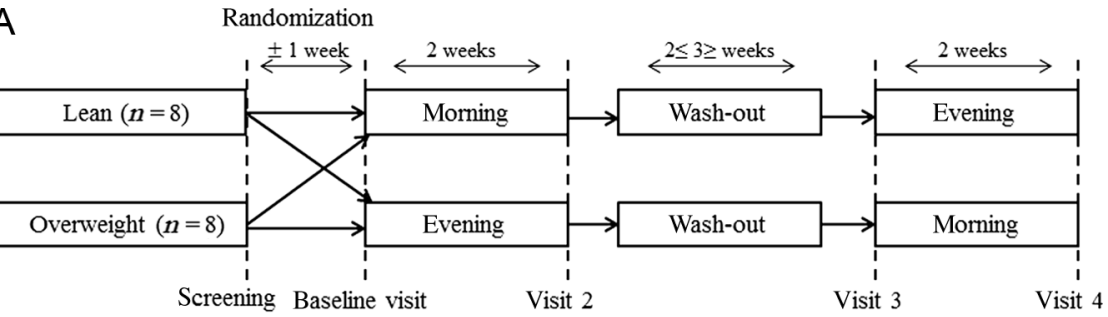

B

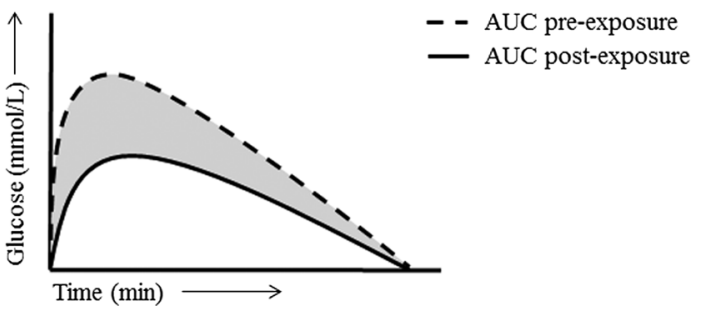

their diet of the 3 days before each visit. On visits 2 and 4 , subjects were asked whether they experienced any side effects; furthermore, adequate use of the bromocriptine was controlled by pill count.

\section{Oral glucose tolerance test and laboratory measurements}

Fasting plasma glucose and insulin values were measured within $2 \mathrm{~min}$ before $t_{0}$. At $t_{0}$, subjects ingested a standardized solution of $75 \mathrm{~g}$ glucose dissolved in $300 \mathrm{~mL}$ water (Added pharma, Oss, The Netherlands). Subsequent measurements took place at $t_{10}, t_{20}, t_{30}, t_{60}, t_{90}$ and $t_{120}$ with $t$ in minutes. Plasma glucose measurements were performed using the HemoCue B-Glucose Analyzer (HemoCue AB, Ängelholm, Sweden). Insulin was measured by chemiluminescent immunometric assay (Immulite 2000, Siemens Healthcare Diagnostic Products).

\section{EE measurement}

Energy expenditure (EE) was measured using a ventilated hood system (Quark RMR Canopy). Subjects were instructed to minimize physical activity (e.g. avoid walking stairs) in the morning before the visit. Before the EE, subjects had to rest for thirty minutes on a bed. During the EE, subjects were not allowed to sleep, talk or move. The EE was performed in a thermoneutral room of approximately $21^{\circ} \mathrm{C}\left(69.8^{\circ} \mathrm{F}\right)$. Respiratory quotient (RQ) and EE values (kcal/day) were measured by indirect calorimetry at 1-min intervals during 20 min after a stable phase had been reached.

\begin{abstract}
Figure 1
Visual explanation of methods. (A) Overview of the visits of the subjects. Subjects came for a screening visit after which they were randomized to the timing of bromocriptine administration. Visits 1 (baseline visit) and 3 were pre-exposure visits. Visits 2 and 4 were post-bromocriptine exposure visits (in randomized order morning and evening administration) for 2 weeks. (B) Graph of the effect of bromocriptine. The effect of bromocriptine administration is the gray area.
\end{abstract}

\section{Outcome measures}

The outcome - differences in effect on insulin sensitivity was expressed by means of various glucose and insulin parameters: areas under the curve (AUCs) for both glucose and insulin, peak values for glucose and insulin during the OGTT and homeostatic model assessment for insulin resistance (HOMA-IR type 1) (fasting insulin $(\mu \mathrm{U} / \mathrm{L}) \times$ fasting glucose $(\mathrm{nmol} / \mathrm{L}) / 22.5)(15)$. Secondary outcomes were the differences in effect of bromocriptine on EE (kcal/day) and weight (kg).

\section{Statistical analysis}

Statistical analysis was performed with IBM SPSS Statistics 22. Data were continuous and not normally distributed; to test for possible statistically significant differences between groups, the Mann-Whitney $U$ test was used for unpaired data and the Wilcoxon signed-rank test for paired data. Values are presented as median and full range. $P<0.05$ was considered statistically significant.

The relative differences $(100 *$ absolute value after exposure)/(absolute value pre-exposure) were used to compare the effect of bromocriptine between the lean and obese subjects.

\section{Results}

We included 8 lean (BMI 21.5 (20.4-21.9) kg/m², age 22.5 (20.3-25.0) years) and 8 obese (BMI 32.1 (29.0-42.0) kg/m², age 22.5 (20.3-25.0) years) healthy Caucasian males (Table 1). All subjects tolerated the drug well.

This work is licensed under a Creative Commons Attribution-NonCommercial-NoDerivs 4.0 International License. 
Table 1 Baseline table.

\begin{tabular}{|c|c|c|c|}
\hline & Lean & Obese & $P$ value \\
\hline$N$ & 8 & 8 & \\
\hline Age (years) & $22.5(20.3-25.0)$ & $23.5(18.5-30.3)$ & 0.88 \\
\hline Body mass index $\left(\mathrm{kg} / \mathrm{m}^{2}\right)$ & $21.5(20.4-21.9)$ & $32.1(29.0-42.0)$ & $<0.001$ \\
\hline Waist circumference $(\mathrm{cm})$ & $79.1(77.3-83.1)$ & $104.0(99.6-135.2)$ & $<0.001$ \\
\hline Fasting plasma glucose (mmol/L) & $4.2(3.9-4.4)$ & $4.3(4.0-4.6)$ & 0.645 \\
\hline Fasting plasma insulin (pmol/L) & $13.8(7.5-26.0)$ & $67.0(32.5-204.5)$ & 0.001 \\
\hline HOMA-IR & $0.35(0.20-0.69)$ & $1.9(1.04-5.70)$ & 0.001 \\
\hline
\end{tabular}

Characteristics of subjects. Data presented as median (interquartile range). BMI, body mass index. Differences between the groups were calculated with the Mann-Whitney $U$ test. HOMA-IR, homeostatic model assessment - insulin resistance, calculated as (glucose (mmol/L) $\times$ insulin $(U / L)) /(22.5)$.

\section{Effect of bromocriptine on insulin and glucose levels during the OGTT}

In lean subjects, there was no effect of bromocriptine administration in the morning on either glucose or insulin values during the OGTT. Bromocriptine administration in the evening resulted in significantly lower glucose values at $t_{30}$ and $t_{90}$ minutes (Fig. 2), but we observed no significant effect on insulin levels.

During the OGTT in obese subjects, bromocriptine administration in the morning resulted in significantly lower glucose values at $t_{20}$ and $t_{30}$ minutes and insulin values at $t_{30}, t_{60}$ and $t_{90}$ minutes. Bromocriptine administration in the evening resulted in significantly lower glucose values at $t_{60}$ minutes (Fig. 3), but no significant effect on insulin was observed.

\section{Effect of bromocriptine on insulin sensitivity}

Lean subjects In lean subjects, only administration of bromocriptine in the evening had a significant effect on fasting insulin sensitivity (fasting HOMA-IR 0.35 $(0.20-0.65)$ vs $0.42(0.18-0.79), P=0.036)$.

Bromocriptine administration in the morning had no significant effect on the AUC for both glucose and insulin. Administration of bromocriptine in the evening led to a significant decrease in the AUC for glucose $(742 \mathrm{mmol} / \mathrm{L} * 120 \mathrm{~min}(695-818)$ vs 641 (504-750), $P=0.036$ ) but not in the AUC for insulin $(32,836 \mathrm{pmol} / \mathrm{L} * 120 \mathrm{~min} \quad(18,823-42,053) \quad$ vs 25,698 $(24,244-42,143), \quad P=0.575) \quad$ compared with the pre-exposure visit.
A
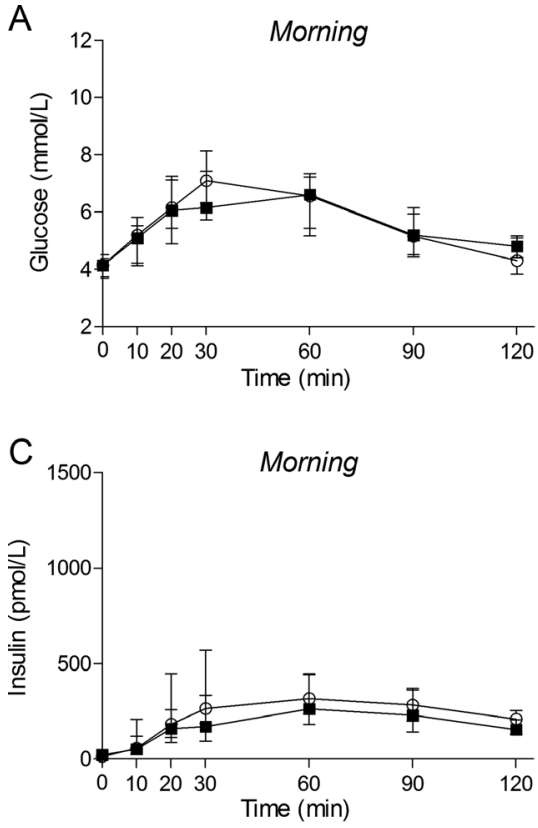
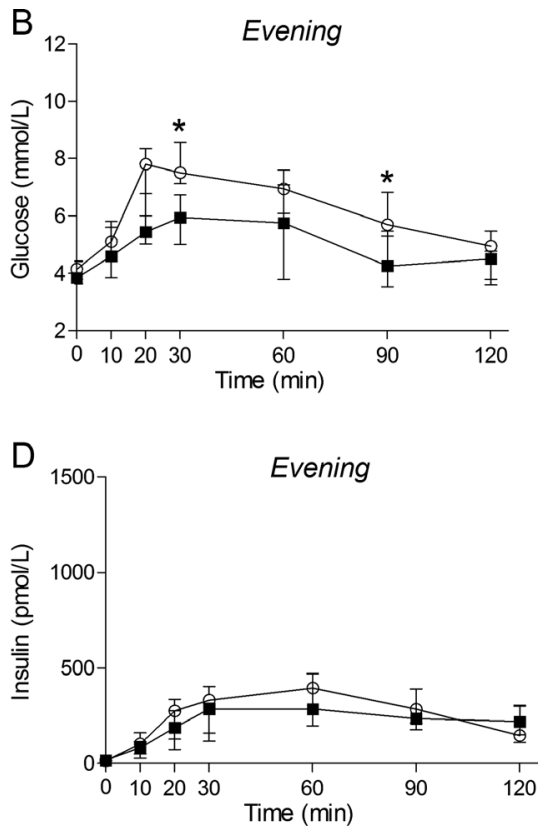

- Pre-exposure

- Post-exposure $\star p<0.05$

\section{Figure 2}

Glucose and insulin values (median + IQR) obtained during the OGTT in lean subjects before the administration of bromocriptine (round icons) and after the administration of bromocriptine (square icons). (A) Glucose values obtained before and after the administration of bromocriptine in the morning. (B) Glucose values obtained before and after the administration of bromocriptine in the evening. (C) Insulin values obtained before and after the administration of bromocriptine in the morning. (D) Insulin values obtained before and after the administration of bromocriptine in the evening.
This work is licensed under a Creative Commons Attribution-NonCommercial-NoDerivs 4.0 International License. 
A
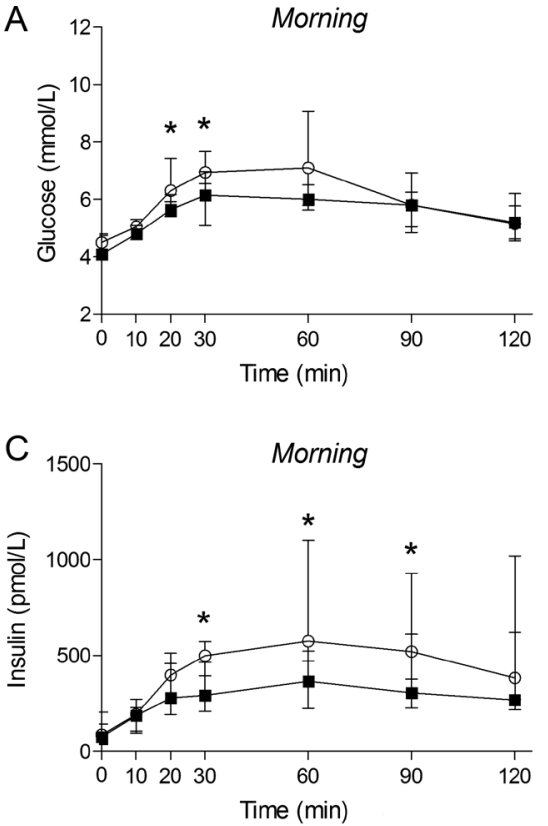

B
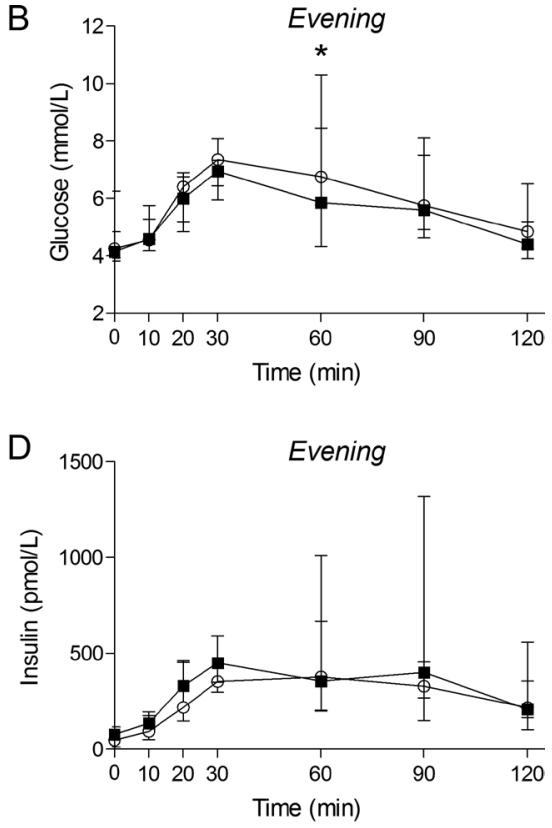

Figure 3

Glucose and insulin values (median + IQR) obtained during the OGTT in obese subjects before the administration of bromocriptine (round icons) and after the administration of bromocriptine (square icons). (A) Glucose values obtained before and after the administration of bromocriptine in the morning. (B) Glucose values obtained before and after the administration of bromocriptine in the evening. (C) Insulin values obtained before and after the administration of bromocriptine in the morning. (D) Insulin values obtained before and after the administration of bromocriptine in the evening.
- Post-exposure

* $p<0.05$
Bromocriptine in the morning or evening had no significant effect on the AUC for HOMA-IR in lean subjects (Table 2).

Obese subjects In obese subjects, variation in the administration of bromocriptine (i.e. morning vs evening) had no significant effect on fasting insulin sensitivity compared with the pre-exposure visits.

Bromocriptine administration in the morning led to a significant decrease in the AUC for insulin $(55,900 \mathrm{mmol} / \mathrm{L}$ * $120 \mathrm{~min} \quad(43,236-96,831)$ vs 36,448 $(25,213-57,711), P=0.012)$ without a significant change in the AUC for glucose $(748 \mathrm{pmol} / \mathrm{L}$ * $120 \mathrm{~min}$ (674-868) vs 669 (620-734), $P=0.069$ ) compared with the pre-exposure visit. The reverse was observed for bromocriptine administration in the evening: a significant decrease in AUC for glucose $(735 \mathrm{mmol} / \mathrm{L} * 120 \mathrm{~min}$ (614-988) vs 644 (568-829), $P=0.017$ ) without a significant change of the AUC for insulin $(35,446 \mathrm{mmol} / \mathrm{L} * 120 \mathrm{~min}$ $(23,694-52,771)$ vs $38,390(25,664-10,4861), P=0.208)$.

The AUC for the HOMA-IRs was significantly lower after bromocriptine administration in the morning (2405 HOMA-IR * 120 min (1649-4655) vs 1229 (896-2348), $P=0.012)$, but not in the evening (1296 HOMA-IR * $120 \mathrm{~min}$ (828-2666) vs 1356 (931-5359), $P=0.401$ ) (Table 2).

\section{Difference in effect of bromocriptine between lean and obese subjects}

To compare the differences in effect of bromocriptine between lean and obese subjects, we calculated the relative effect compared with the pre-exposure visit.

Fasting HOMA-IR values improved significantly more in obese subjects compared with those in the lean subjects when bromocriptine was administered in the morning (100\% (73-119) vs 69\% (53-81), $P=0.050)$ but not in the evening (90\% (39-115) vs 104\% (90-162), $P=0.083)$.

There was no difference in effect of bromocriptine administration between lean and obese subjects on glucose AUC. The insulin AUC values decreased significantly more in obese subjects than those in the lean subjects when bromocriptine was administered in the morning (114\% (77-133) vs 58\% (47-71), $P=0.015)$ but not in the evening (90\% (65-131) vs 111\% (95-177), $P=0.401)$.

The AUC for the HOMA-IRs decreased significantly more in obese subjects than that in the lean subjects when bromocriptine was administered in the evening (114\% (87-256) vs 82\% (59-99), $P=0.050)$ but not in the morning $(88 \%(75-131)$ vs $174 \%(104-243)$, $P=0.401$ ) (Table 3). http://www.endocrineconnections.org DOI: 10.1530/EC-16-0051
() 2016 The authors Published by Bioscientifica Ltd
This work is licensed under a Creative Commons Attribution-NonCommercial-NoDerivs 4.0 International License. 


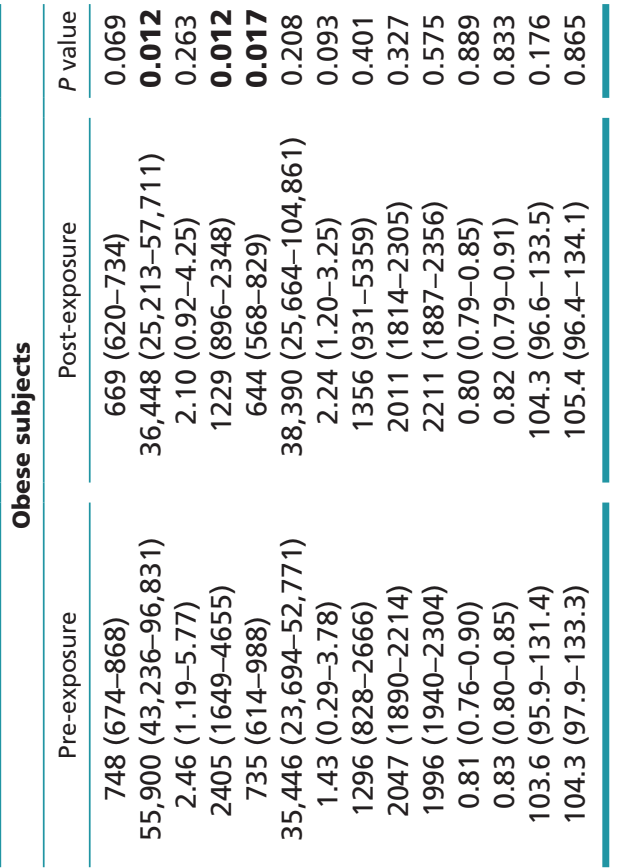

\section{Effect of bromocriptine on energy expenditure, weight and diet}

Bromocriptine administration in the morning or evening had no effect on EE, RQ or weight in both obese and lean subjects (Table 2). There were no changes in diet, which could explain for the differences found in insulin sensitivity.

\section{Discussion}

In this study, we assessed the effect of bromocriptine administration on insulin sensitivity. We compared the effect between lean and obese subjects and between drug administration in the morning and evening. We confirm that bromocriptine administration improved insulin sensitivity in obese subjects, independent of the time of administration. The results found in lean subjects were ambiguous, there was a positive effect on insulin sensitivity of administration in the evening (i.e. lowered glucose AUC without significant changes of the AUC for insulin). However, fasting insulin sensitivity worsened in lean subjects when the bromocriptine was administered in the evening.

In lean subjects, bromocriptine administration in the evening resulted in a better overall insulin sensitivity, compared with the pre-exposure visit. Remarkably, fasting insulin sensitivity was significantly lower after bromocriptine administration in the evening. So, fasting insulin sensitivity diminished, whereas post-prandial insulin sensitivity increased. Indeed, bromocriptine is thought to promote post-prandial glucose disposal after a glucose load (e.g. a meal or an oral glucose tolerance test) $(3,16)$, which could explain the improvements seen in insulin sensitivity during the OGTT. Furthermore, healthy individuals show diurnal changes in insulin sensitivity and glucose metabolism (17). Glucose tolerance deteriorates in the evening with a decrease in insulin sensitivity and a reduced $\beta$-cell responsiveness to glucose (18). Circadian neuroendocrine rhythms of both dopamine and noradrenaline play a pivotal role in insulin sensitivity $(12,13)$ and are considered to be still intact in lean subjects. In lean subjects, dopamine physiologically peaks in the morning $(14,19)$.

Bromocriptine stimulates $\mathrm{D}_{2}$-receptors, both presynaptically and postsynaptically. The presynaptic $\mathrm{D}_{2}$ receptor is located on the cell body of dopaminergic cells, and stimulation of this receptor reduces dopamine release (feedback mechanism). The postsynaptic receptor is located at the nerve terminal level, on non-dopaminergic

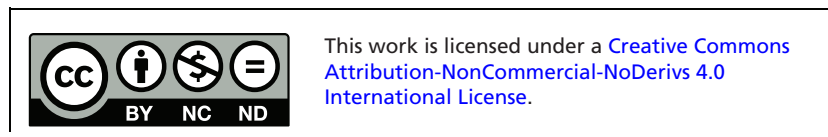


Table 3 Bromocriptine effect in lean vs obese.

\begin{tabular}{|c|c|c|c|}
\hline & Lean & Obese & $P$ value \\
\hline Glucose AUCm (mmol/L *120 min) & 106 (91-115) & $86(81-106)$ & 0.382 \\
\hline Insulin AUCm (pmol/L *120 min) & $100(73-119)$ & $69(53-81)$ & 0.050 \\
\hline HOMA-IRm & $114(77-133)$ & $58(47-71)$ & 0.015 \\
\hline HOMA-IR AUCm & $88(75-131)$ & $174(104-243)$ & 0.083 \\
\hline Glucose AUCe $(\mathrm{mmol} / \mathrm{L}$ * $120 \mathrm{~min})$ & $93(62-100)$ & $91(81-97)$ & 1.000 \\
\hline Insulin AUCe (pmol/L * $120 \mathrm{~min})$ & $90(65-131)$ & $111(95-177)$ & 0.401 \\
\hline HOMA-IRe & $90(39-115)$ & $104(90-162)$ & 0.083 \\
\hline HOMA-IR AUCe & $114(87-256)$ & 82 (59-99) & 0.050 \\
\hline
\end{tabular}

Data presented as median (interquartile range). This table shows the relative differences as compared with the pre-exposure visit (e.g. pre-exposure visit $=100 \%$ ). Differences between the groups were calculated with the Mann-Whitney $U$ test. HOMA-IR, homeostatic model assessment - insulin resistance, calculated as (glucose $(\mathrm{mmol} / \mathrm{L}) \times$ insulin $(\mathrm{U} / \mathrm{L})) /(22.5)$. Bold indicated statistical significance $(P<0.05)$.

neurons or tissues, and plays a major role in dopamine signaling. Because bromocriptine directly stimulates dopamine $\mathrm{D}_{2}$-receptors, the overall clinical effect of bromocriptine administration is mainly related to the effects on the postsynaptic receptor (20), and to a lesser extent to discrete lowering of dopamine concentration via stimulation of $\mathrm{D}_{2}$-autoreceptors.

So, in healthy controls small changes in dopamine concentration and/or occupancy of the dopamine $\mathrm{D}_{2}$-receptor postsynaptically, most likely will not have a large effect. However, in the evening, when the dopamine levels are lower, relatively small changes in both dopamine concentration and/or occupancy of the dopamine $\mathrm{D}_{2}$-receptor postsynaptically may result in a larger (measurable) effect.

The effects of the $\mathrm{D}_{2}$ agonist bromocriptine were more pronounced in obese compared with healthy controls. Bromocriptine administration in obese subjects led to an increased insulin sensitivity independent of the timing of the administration.

Interestingly, imaging studies showed quite consistently lower striatal dopamine $\mathrm{D}_{2 / 3}$-receptor binding in obese compared with non-obese subjects, which supports the hypothesis of a hypo-dopaminergic state in obese subjects (21). This lower $\mathrm{D}_{2 / 3}$-receptor binding can be explained by a lower expression and/or lower binding capacity for dopamine due to obesity-related conformational changes of the receptor (e.g., increased sensitivity of the receptor for dopamine). Because the insulin sensitivity is most likely related to an altered dopaminergic state, the effects of bromocriptine were expected to be more pronounced in obese compared with non-obese subjects. This is also illustrated when directly comparing the effects of bromocriptine between the lean and obese subjects in our study, showing that the effect of bromocriptine administration in obese subjects was more pronounced than in lean subjects.
The diurnal changes in insulin sensitivity and glucose metabolism, which are apparent in healthy individuals, are diminished or lost in obese patients with persistent insulin resistance (22).

Despite the fact that our obese subjects were normoglycemic, they were significantly less insulin sensitive than the lean control group. So, their circadian dopamine rhythm might be disturbed, and the timed administration of bromocriptine in the morning might have restored the diminished circadian dopamine peak and thereby improved insulin sensitivity $(3,16)$. Indeed, administering bromocriptine within $2 \mathrm{~h}$ after waking up, has been shown to prevent or even reverse insulin resistance in humans (23), because it mimics the physiological peak of dopamine in the morning.

In this study, we were unable to confirm the results found in our previous study, in which bromocriptine administration led to a decreased insulin sensitivity in young, healthy and lean subjects (11). A reason for this might be the difference in time when the OGTT was performed. In our previous study, the OGTT was performed at the end of the testing day in the afternoon, whereas in this study the OGTTs were performed in the morning. Both duration of fasting preceding the OGTT and the time of the day might affect the results of the OGTT (24). Furthermore, carbohydrate intake preceding the OGTT might also influence the results of the OGTT (25).

This study has several limitations. Due to the relative small sample size, external influences have a relatively large impact. Nonetheless, there were no significant changes in diet, which could explain for the differences found, subjects did not alter their lifestyle during the trial (e.g. physical activity, alcohol consumption, sleeping habits), and none of the subjects became ill during the trial.

Furthermore, we used an open-label randomization; this might have influenced the behavior of the subjects

This work is licensed under a Creative Commons Attribution-NonCommercial-NoDerivs 4.0 International License. 
and in such way that it may have influenced the results. However, the randomized order of bromocriptine administration has helped to prevent this possible effect, and there were no changes in diet during the trial.

We used a standard bromocriptine preparation instead of a quick-release variant. Standard bromocriptine preparations differ from the quick-release variant in its pharmacokinetics (e.g. bioavailability, peak levels) (16). The tablets were taken unsupervised at home, which may have resulted in inadequate use of the bromocriptine. However, the pill count was correct for all subjects and therefore the chance of inadequate use seems to be small. The daily bromocriptine dose administrated was $1.25 \mathrm{mg}$ (orally) during each first week and $2.50 \mathrm{mg}$ during each second week. Both the treatment period as well as the used dosages may not have brought out full therapeutic effects, leading to an underestimation of the effect because the recommended dose used to treat diabetes mellitus type 2 is $4.8 \mathrm{mg}$ of the quick-release formulation. Furthermore, we used standard dosing of bromocriptine, so there was no difference in dosing between the lean and obese subjects; the bromocriptine dosage was not corrected for BMI or bodyweight. However, a correction of the bromocriptine dosage according to BMI or bodyweight would have resulted in higher dosages for the obese subjects and would most likely have resulted in larger effects compared with the lean subjects. So, if anything, our results most likely underestimate the effect of bromocriptine in obese subjects. Nonetheless, future studies are needed to determine whether BMI or bodyweight influences the effect of bromocriptine and whether this has consequences for the administration of bromocriptine in clinical practice.

Lastly, the results we found apply to Caucasian, young, male subjects. It is unknown whether they can be translated to the general population. Nonetheless, our results are in line with the effect of bromocriptine on insulin sensitivity found in other trials.

\section{Conclusion}

Bromocriptine increases insulin sensitivity in both lean and obese subjects. In lean subjects, this effect was only apparent when bromocriptine was administrated in the evening, whereas in obese subjects, insulin sensitivity increased, independent of the timing of bromocriptine administration.

\section{Declaration of interest}

The authors declare that there is no conflict of interest that could be perceived as prejudicing the impartiality of the research reported.

\section{Funding}

This work did not receive any specific grant from any funding agency in the public, commercial, or not-for-profit sector.

\section{Authors' contribution statement}

L B contributed to conception, design, analysis and interpretation of data and drafting of the article. H J V contributed to conception, design, analysis and interpretation of data and critically revised the manuscript for important intellectual content. R T contributed to design, analysis of data and critical revision for important intellectual content. J B contributed to design, analysis and interpretation of data and critical revision for important intellectual content. J B H contributed to conception, analysis and interpretation of data and critical revision for important intellectual content. F H contributed to conception, design, analysis and interpretation of data and critical revision for important intellectual content.

\section{Acknowledgements}

The authors thank Tom van den Ende, medical student at the department of Internal Medicine in the Academic Medical Center, for his assistance during the research visits.

\section{References}

1 American Diabetes Association. Standards of medical care in diabetes 2008. Diabetes Care 200831 (Supplement 1) S12-S54. (doi:10.2337/ dc08-s012)

2 Tan EK \& Jankovic J. Choosing dopamine agonists in Parkinson's disease. Clinical Neuropharmacology 200124 247-253. (doi:10.1097/00002826-200109000-00001)

3 Pijl H, Ohashi S, Matsuda M, Miyazaki Y, Mahankali A, Kumar V, Pipek R, Iozzo P, Lancaster JL, Cincotta AH, et al. Bromocriptine: a novel approach to the treatment of type 2 diabetes. Diabetes Care 200023 1154-1161. (doi:10.2337/diacare.23.8.1154)

4 Aminorroaya A, Janghorbani M, Ramezani M, Haghighi S \& Amini M. Does bromocriptine improve glycemic control of obese type-2 diabetics? Hormone Research 200462 55-59. (doi:10.1159/000078932)

5 Cincotta AH, Meier AH \& Cincotta M Jr. Bromocriptine improves glycaemic control and serum lipid profile in obese Type 2 diabetic subjects: a new approach in the treatment of diabetes. Expert Opinion on Investigational Drugs 19998 1683-1707. (doi:10.1517/13543784.8. 10.1683)

6 Vinik AI, Cincotta AH, Scranton RE, Bohannon N, Ezrokhi M \& Gaziano JM. Effect of bromocriptine-QR on glycemic control in subjects with uncontrolled hyperglycemia on one or two oral antidiabetes agents. Endocrine Practice 201218 931-943. (doi:10.4158/ EP12187.OR)

7 Meier AH, Cincotta AH \& Lovell WC. Timed bromocriptine administration reduces body fat stores in obese subjects and hyperglycemia in type II diabetics. Experientia 199248 248-253. (doi:10.1007/BF01930467)

8 Kok P, Roelfsema F, Frolich M, van Pelt J, Stokkel MP, Meinders AE $\&$ Pijl H. Activation of dopamine D2 receptors simultaneously ameliorates various metabolic features of obese women. American Journal of Physiology: Endocrinology and Metabolism 2006291 E1038-E1043. (doi:10.1152/ajpcell.00266.2006) 
9 Kamath V, Jones CN, Yip JC, Varasteh BB, Cincotta AH, Reaven GM \& Chen YD. Effects of a quick-release form of bromocriptine (Ergoset) on fasting and postprandial plasma glucose, insulin, lipid, and lipoprotein concentrations in obese nondiabetic hyperinsulinemic women. Diabetes Care 199720 1697-1701. (doi:10.2337/diacare.20.11.1697)

10 Cincotta $\mathrm{AH} \&$ Meier AH. Bromocriptine (Ergoset) reduces body weight and improves glucose tolerance in obese subjects. Diabetes Care 199619 667-670. (doi:10.2337/diacare.19.6.667)

11 Bahler L, Verberne HJ, Soeters MR, Booij J, Hoekstra JB \& Holleman F. Dopaminergic Effects on Brown Adipose Tissue (DEBAT): a prospective physiological study. Diabetes and Metabolism 2016 [in press]. (doi:10.1016/j.diabet.2016.06.003)

12 Southern LL, Cincotta AH, Meier AH, Bidner TD \& Watkins KL. Bromocriptine-induced reduction of body fat in pigs. Journal of Animal Science 199068 931-936. (doi:10.2527/1990.684931x)

13 Cincotta AH, Schiller BC, Landry RJ, Herbert SJ, Miers WR \& Meier AH. Circadian neuroendocrine role in age-related changes in body fat stores and insulin sensitivity of the male Sprague-Dawley rat. Chronobiology International 199310 244-258. (doi:10.1080/07420529309059707)

14 Meier AH \& Cincotta AH. Circadian rhythms regulate the- expression of the thrifty genotype/phenotype. Diabetes Reviews 19964 464-487.

15 Matthews DR, Hosker JP, Rudenski AS, Naylor BA, Treacher DF $\&$ Turner RC. Homeostasis model assessment: insulin resistance and beta-cell function from fasting plasma glucose and insulin concentrations in man. Diabetologia 198528 412-419. (doi:10.1007/ BF00280883)

16 Scranton R \& Cincotta A. Bromocriptine - unique formulation of a dopamine agonist for the treatment of type 2 diabetes. Expert Opinion on Pharmacotherapy 201011 269-279. (doi:10.1517/14656560903501544)

17 Boden G, Ruiz J, Urbain JL \& Chen X. Evidence for a circadian rhythm of insulin secretion. American Journal of Physiology 1996271 E246-E252.
18 Lee A, Ader M, Bray GA \& Bergman RN. Diurnal variation in glucose tolerance. Cyclic suppression of insulin action and insulin secretion in normal-weight, but not obese, subjects. Diabetes 199241 750-759. (doi:10.2337/diab.41.6.750)

19 Canale MP, Manca di Villahermosa S, Martino G, Rovella V, Noce A, De Lorenzo A \& Di Daniele N. Obesity-related metabolic syndrome: mechanisms of sympathetic overactivity. International Journal of Endocrinology 20132013 865965. (doi:10.1155/2013/865965)

20 Seeman P. Parkinson's disease treatment may cause impulse-control disorder via dopamine D3 receptors. Synapse 201569 183-189. (doi:10.1002/syn.21805)

21 van der Zwaal EM, de Weijer BA, van de Giessen EM, Janssen I, Berends FJ, van de Laar A, Ackermans MT, Fliers E, la Fleur SE, Booij J, et al. Striatal dopamine D2/3 receptor availability increases after long-term bariatric surgery-induced weight loss. European Neuropsychopharmacology 201626 1190-1200. (doi:10.1016/j. euroneuro.2016.04.009

22 Boden G, Chen X \& Polansky M. Disruption of circadian insulin secretion is associated with reduced glucose uptake in first-degree relatives of patients with type 2 diabetes. Diabetes 199948 2182-2188. (doi:10.2337/diabetes.48.11.2182)

23 Lopez Vicchi F, Luque GM, Brie B, Nogueira JP, Garcia Tornadu I $\&$ Becu-Villalobos D. Dopaminergic drugs in type 2 diabetes and glucose homeostasis. Pharmacological Research 2016109 74-80. (doi:10.1016/j.phrs.2015.12.029)

24 Service FJ, Hall LD, Westland RE, O'Brien PC, Go VL, Haymond MW \& Rizza RA. Effects of size, time of day and sequence of meal ingestion on carbohydrate tolerance in normal subjects. Diabetologia 198325 316-321. (doi:10.1007/bf00253193)

25 Kaneko T, Wang PY, Tawata M \& Sato A. Low carbohydrate intake before oral glucose-tolerance tests. Lancet 1998352289. (doi:10.1016/S0140-6736(05)60263-2)

Received in final form 8 September 2016

Accepted 10 October 2016

Accepted Preprint published online 10 October 2016 http://www.endocrineconnections.org DOI: 10.1530/EC-16-0051
(C) 2016 The authors Published by Bioscientifica Ltd
This work is licensed under a Creative Commons Attribution-NonCommercial-NoDerivs 4.0 International License. 